\title{
LENIÇÃO E EPÊNTESE EM GRUPOS CONSONANTAIS TAUTOSSILÁBICOS NA LÍNGUA POLONESA FALADA EM CRUZ MACHADO, PARANÁ
}

\author{
Sônia Eliane Niewiadomski \\ Mestranda em Letras pela Universidade Estadual do Centro-Oeste (UNICENTRO) \\ soniaeliane@gmail.com
}

Luciane Trennephol da Costa

Doutora em Letras (Estudos Linguísticos) pela Universidade Federal do Paraná (UFPR)

Professora Adjunta da Universidade Estadual do Centro-Oeste (UNICENTRO)

luciane.tcosta@yahoo.com.br

\section{RESUMO}

Este trabalho apresenta (parte dos resultados de um estudo que objetiva descrever o polonês falado no interior do Paraná). Analisamos acusticamente os fenômenos de lenição e a inserção ou não da epêntese vocálica nos encontros de sons consonantais tautossilábicos, inexistentes no $\mathrm{PB}$, como, por exemplo, "gdzie" [g $\widehat{\mathrm{d} z} \varepsilon$ ] (onde) no polonês falado em uma comunidade de descendentes no interior de Cruz Machado (PR), mais especificamente no Rio do Banho. A maioria desses descendentes é bilíngue (português/polonês) e, até os dias de hoje, têm como língua materna o polonês. Foram analisados dados de fala de oito informantes, sendo quatro homens e quatro mulheres, divididos em duas faixas etárias: de 25 até 40 anos e mais de 60 anos. A observação dos dados deu-se através de análise acústica e os resultados indicam a manutenção do sistema do polonês pelos descendentes. O estudo contribui para o conhecimento e registro dessa língua brasileira.

Palavras-chave: polonês, línguas brasileiras, análise acústica, sons consonantais, descrição.

\section{ABSTRACT}

This study shows the partial results from an ongoing research that seeks to describe the spoken Polish in the countryside of the state of Paraná, in Brazil. We analyzed acoustically the lenition phenomena and the insertion or not of the vowel epenthesis in the encounters of tautosyllabic consonant sounds that are not present in the Brazilian Portuguese, as for instance, "gdzie" [gब $\widehat{d z} \varepsilon$ ] (where) in the spoken Polish from the community of Polish descendants of Cruz Machado in Paraná, specifically in the Rio do Banho region. The vast majority of this descendants are bilinguals (Portuguese/Polish) and, to this day, have Polish as their first language. Data from eight informants was analyzed, being four males and four females, divided into two age groups as follows: from 25 to 40 and more than 60 years old. The data observation was done by acoustic analysis and the results point to the maintenance of the Polish system by the descendants. The study adds knowledge and registry enrichment of the Brazilian language.

Keywords: polish, brazilian languages, acoustic analysis, consonantal sounds, description. 


\section{Introdução}

Para existir uma língua é necessário que haja seres humanos (BAGNO, 2007, p. 9). Sendo assim, toda língua em uso por uma comunidade de falantes pode sofrer variações e transformações, pois não pode ser considerada como um elemento neutro ou cristalizado, longe das interferências de outras línguas. O contato linguístico entre dois sistemas pode os influenciar mutuamente. Assim, não estamos só nos referindo ao contato entre as línguas, mas de culturas que passam a coexistir.

Ao longo da história do Brasil, que foi povoado por diversos grupos étnicos, encontramos diversas situações de contato linguístico. Na colonização do Brasil, os portugueses entraram em contato com os falantes de línguas indígenas (autóctones). $\mathrm{Na}$ época da escravidão, o português entrou em contato com as línguas africanas, cujos sistemas linguísticos eram impedidos de serem falados. No momento do povoamento das terras vastas do Brasil com as migrações europeias e asiáticas, essas línguas entram com o português. Os referidos momentos históricos do Brasil promoveram o contato de diferentes culturas e sistemas linguísticos e consequentemente a coexistência de várias línguas em nosso país. Isso significa que, se olharmos para a história do país e para o atual contexto, o Brasil é um território plurilingue.

O Brasil é considerado um país com grande diversidade linguística, em cujo território são faladas em torno de 200 línguas, segundo dados levantados pelo Censo IBGE $^{\mathrm{i}}$ de 2010. De acordo com Altenhofen (2004) calcula-se a existência de aproximadamente 170 línguas ainda faladas pelos indígenas e 30 alóctones (línguas de imigrantes). 
Esse cenário compõe o rico mosaico linguístico brasileiro, além do português, cuja língua é majoritária e oficial, há outras inúmeras línguas coexistindo em nosso território, como o guarani, o talian, o pomerano, o ucraniano, o polonês entre outras.

O Paraná é um estado pluriétnico, pois recebeu muitos imigrantes dentre eles, os alemães, os italianos, os poloneses, os ucranianos, os holandeses, os russos, os japoneses etc. A região sudeste do Paraná é caracterizada pela emigração eslava, polonesa e ucraniana, nessas comunidades a cultura eslava continua viva e os descendentes preservam as tradições de seus antepassados, seja na culinária, nos ritos religiosos, no artesanato típico, nas crenças e, principalmente, nos sistemas linguísticos trazidos pelos seus ancestrais. A maioria desses descendentes é bilíngue e/ou trilíngue, (polonês/português, ucraniano/português e polonês/ucraniano/português) e até os dias de hoje a língua materna de alguns desses falantes não é o português e sim uma das línguas eslavas (COSTA; LOREGIAN-PENKAL, 2015). As práticas linguísticas são mais frequentes nas cidades mais interioranas como Cruz Machado, Mallet, Prudentópolis entre outras, distantes da capital Curitiba. A língua eslava predomina no uso diário, na igreja, no trabalho do campo e na família.

Diante desse mosaico cultural e dessa realidade linguística, o presente trabalho, fruto de uma parte da dissertação de mestrado, descreve o polonês falado em Cruz Machado, mais especificamente na comunidade do Rio do Banho, analisando os fenômenos da lenição e da inserção ou não de um elemento vocálico entre encontros de sons consonantais, inexistentes no português brasileiro ancorado teoricamente na Teoria Acústica da Fala (FANT, 1960; KENT; READ, 1992).

\section{Cruz Machado}


Os poloneses se espalharam ao redor do mundo e a maioria dos que emigraram aos países da América Latina eram "colonos camponeses". De acordo com Mazurek (2016), a partir das últimas décadas do século XIX, a emigração se intensificou à Argentina e ao Brasil e teve continuidade ainda após a I Guerra Mundial. Dessa forma, estima-se que aproximadamente 110 mil poloneses dirigiram-se ao Brasil, ocupando sobretudo as colônias rurais nos estados do sul do país (MAZUREK 2016, p. 41). É preciso destacar que durante esse mesmo período o Brasil também recebia outros grupos de emigrantes da Europa.

A maior onda emigratória se estabeleceu no sul do Brasil, principalmente nos estados do Paraná, Rio Grande do Sul e Santa Catarina, no meio rural desses estados, cujas áreas eram cobertas pela mata e de difícil acesso. O Paraná foi o estado que mais recebeu emigrantes poloneses.

Em julho de 1911, estabeleceram-se no núcleo colonial Cruz Machado (hoje Pátio Velho) os primeiros colonizadores poloneses provenientes sobretudo da região de Lubelszczyzna (região sudeste da Polônia, ocupada pela Rússia) das cidades de Siedlce, Lublin, Chełm e Białystok. As áreas escolhidas para a colonização localizam-se nas proximidades da linha ferroviária de Mallet, aproximadamente $50 \mathrm{~km}$. Conforme Dvorak (2013), estima-se que se estabeleceram no núcleo colonial Cruz Machado, em 1911, em torno de 861 famílias, aproximadamente 5.500 pessoas.

Segundo o Censo Demográfico de 2010, realizado pelo Instituto Brasileiro de Geografia e Estatística (IBGE) ${ }^{\mathrm{ii}}$, o município de Cruz Machado, situado no sudeste do Paraná, localizado aproximadamente $300 \mathrm{~km}$ da capital (Curitiba), possui uma população de aproximadamente 18.040 habitantes. Ainda com base nesses dados, podemos 
identificar uma forte predominância populacional na zona rural, cerca de 11.983 habitantes, enquanto na zona urbana 6.057 habitantes, o que representa um percentual de $66 \%$ e $34 \%$ para as zonas rural e urbana, respectivamente.

Por mais de um século, a língua polonesa mantém sua vitalidade no município de Cruz Machado, sendo a língua materna da maioria dos descendentes. Entretanto, não há estudos descritivos acerca dessa língua de herança nessa localidade. Dessa forma, o objetivo deste trabalho é descrever os encontros de sons consonantais tautossilábicos no polonês falado em Cruz Machado, verificando se há inserção de epêntese vocálica ou a ocorrência do fenômeno de lenição. A nossa pesquisa contribui para o conhecimento da realidade linguística da região sul do Brasil, visando à descrição da língua polonesa falada no Brasil, especificamente no município de Cruz Machado, no Paraná.

\section{Metodologia}

O corpus utilizado nesta pesquisa pertence ao Banco de dados do Laboratório de Fonética do Núcleo de Estudos Eslavos da Universidade Estadual do Centro-Oeste. Utilizamos dois protocolos diferentes de coleta de dados, um por estímulo visual e outro por leitura de frase veículo.

No estímulo visual, apresentamos uma sequência de 26 imagens, (apresentação de slides) para que os informantes falassem em polonês o que viam, logo após cada imagem ser projetada. Já na leitura de frase-veículo, mostramos uma lista de palavras em português (45 vocábulos apresentados por meio de slides), as quais as informantes deveriam produzir em polonês, inseridas na seguinte frase-veículoiii POWIEDZ 
PRȨDKO (em português fale rápido), da qual serão posteriormente recortados os sons para análise.

Na montagem do corpus atentamos para a escolha de vocábulos de uso cotidiano referentes ao trabalho dos informantes na agricultura. Por isso, evitamos palavras que não fossem familiares aos participantes.

Uma vez aplicado o teste de imagens, em seguida, passamos para o segundo procedimento, da fala controlada utilizando frase-veículo. Primeiramente, cada informante teve um tempo para a familiarização com o protocolo, de modo que a fala fosse semi-espontânea. Gravamos quatro repetições para cada informante de ambos os procedimentos.

Nesta pesquisa, foram analisados dados de fala de oito informantes descendentes de poloneses, sendo quatro do sexo feminino e quatro do sexo masculino, divididos em duas faixas etárias: de 25 até 40 anos e mais de 60 anos. Todos os informantes têm o polonês como primeira língua, falam e entendem e dois participantes sabem ler e escrever. A gravação dos dados foi registrada por meio de um gravador digital e microfone unidirecional acoplado, nas residências dos informantes, localizada na comunidade Rio do Banho. O quadro 1 apresenta as informações detalhadas de todos os informantes da pesquisa. 
Quadro 1 - Perfil dos informantes

\begin{tabular}{|c|c|c|c|c|c|c|}
\hline \multicolumn{7}{|c|}{ Informantes } \\
\hline Iniciais & Sexo & Idade & Profissão & Escolaridade & $\begin{array}{c}\text { Grau de } \\
\text { língua } \\
\text { conhecimento } \\
\text { do polonês }\end{array}$ \\
\hline 1.AD & $\mathrm{M}$ & 39 anos & Agricultor & $\begin{array}{c}\text { Ens. Fundamental } \\
\text { incompleto }\end{array}$ & polonês & Entende e fala \\
\hline 2.ID & $\mathrm{F}$ & 89 anos & Aposentada & Primário completo & polonês & $\begin{array}{c}\text { Entende, fala, } \\
\text { escreve e lê }\end{array}$ \\
\hline 3.RN & $\mathrm{M}$ & 39 anos & Agricultor & Ens. Fundamental & polonês & Entende e fala \\
\hline 4.AD & $\mathrm{F}$ & 37 anos & Dona de casa & $\begin{array}{c}\text { Ens. Fundamental } \\
\text { incompleto }\end{array}$ & polonês & Entende e fala \\
\hline 5.AS & $\mathrm{M}$ & 61 anos & Agricultor & Primário completo & polonês & Entende e fala \\
\hline 6.EB & $\mathrm{F}$ & 26 anos & Dona de casa & Ens. fundamental & polonês & Entende e fala \\
\hline 7.LL & $\mathrm{M}$ & 70 anos & Aposentado & Primário completo & polonês & $\begin{array}{c}\text { Entende, fala, } \\
\text { escreve e lê }\end{array}$ \\
\hline 8.IL & $\mathrm{F}$ & 68 anos & Aposentada & Primário completo & polonês & Entende e fala \\
\hline
\end{tabular}

Os detalhes fonéticos foram observados por meio de análise fonética acústica com o software PRAAT ${ }^{\mathrm{iv}}$ (BOERSMA; WEENINK, 2016). Esse software foi desenvolvido por Paul Boersma e David Weenink, ambos linguistas do Instituto de Ciências Fonéticas da Universidade de Amsterdã. Neste trabalho, apresentaremos especificamente os resultados para a produção de encontros consonantais tautossilábicos na língua polonesa falada em Cruz Machado, Paraná (PR).

\section{Fenômenos de lenição e epêntese vocálica no polonês falado em Cruz Machado}

Os sistemas sonoros das línguas portuguesa e polonesa apresentam diferenças substanciais. O sistema vocálico do português brasileiro, doravante PB, e da língua polonesa diferem-se quanto às vogais médias altas, o sistema vocálico do polonês não apresenta as vogais médias altas [e o] como no PB. De acordo com Gussmann (2007) o polonês possui seis vogais orais [i $\dot{i} \varepsilon$ a u J]. Enquanto, no português falado no Brasil, 
Câmara Jr (1970) identifica sete sons vocálicos [a, e, ع, i, o, J, u]. Já o sistema consonantal do polonês, apresenta oclusivas, nasais, fricativas, africadas e laterais. No que se refere às fricativas, o polonês possui um número maior que o PB: labio-dentais [f, v], dentais [s, z], alveolo-palatais [s, z] pós-alveolares [ $[, 3]$, velar [x] e as africadas dentais [ts, dz], alveolopalatais [ts, dz] e as africadas pós-alveolares [t], dz] (GUSSMANN 2007, p. 5-6).

Isso significa que, na língua polonesa, as fricativas apresentam três pontos de articulação adicionais em relação à língua portuguesa - dental, pós-alveolar retroflexo e palatalizada pós-alveolar. Diferentemente do PB, que compreende labiodentais, alveolares e palatais.

Quadro 2 - Fricativas e africadas no polonês

\begin{tabular}{|c|c|c|c|c|c|}
\hline Ponto & Lábiodental & Dentais & $\begin{array}{l}\text { Alveolo- } \\
\text { palatais }\end{array}$ & $\begin{array}{c}\text { Pós- } \\
\text { alveolares }\end{array}$ & Velar \\
\hline Africada & & $\begin{array}{l}\text { ts } \\
\mathrm{dz}\end{array}$ & ts $\quad d z$ & t $\quad d 3$ & \\
\hline Fricativa & $f$ & s & S & $\int$ & $x$ \\
\hline
\end{tabular}

Fonte: adaptado conforme informações de GUSSMANN 2007, p. 5-6.

Além das diferenças no nível segmental, as duas línguas apresentam também diferenças no nível suprassegmental. No português brasileiro, o ataque complexo é bastante restrito, permitindo como segundo elemento uma lateral ou um rótico. No PB, os encontros tautossilábicos ocorrem em uma mesma sílaba e são formados tipicamente por uma obstruinte e uma líquida (C+líquida) - sílabas CCV (consoante + consoante + vogal), diferentemente do polonês. No português brasileiro, a obstruinte em um encontro consonantal tautossilábico pode ser uma das consoantes $[p, b, t, d, k, g, f, v]$ e a consoante líquida pode ser [I] ou [r] (SILVA, 2010). 
A estrutura silábica da língua polonesa permite até cinco consoantes no encontro consonantal, como, por exemplo, a palavra państwo ['panstfo] (senhores) com encontro consonantal de quatro sons consonantais. No polonês falado em Cruz Machado, encontramos essa estrutura silábica, por exemplo, na sequência da palavra pszczoła [pfţ่owa] (abelha), cuja estrutura não é comum no PB, caracterizada por uma oclusiva,

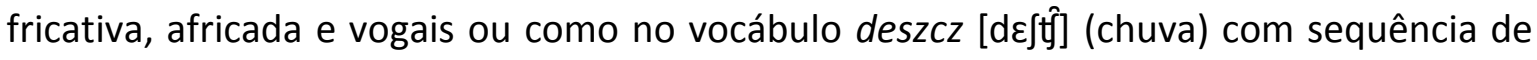
fricativa []] e africada [t].

Em relação à sílaba, Oliveira (2017) reforça que, no PB, "se algum padrão silábico não é comum, os falantes tendem a inserir ou apagar segmentos. No caso da inserção, temos o fenômeno da epêntese. No caso do apagamento, temos a lenição" (OLIVEIRA, 2017, p. 16).

Câmara Jr. (1970) aponta a presença da epêntese em grupos complexos de consoantes, ou seja, a existência de um segmento vocálico entre os encontros consonantais em sequências como nas seguintes palavras: ptose, afta, advogado. Assim, segundo ele, o vocábulo "afta" no PB é produzido como [afita]. Sendo assim, palavras como compacto, apto, ritmo, "foram introduzidas através da língua escrita, a partir do século XV, como empréstimo ao latim clássico" e apresentam entre os encontros de som consonantal a "intercalação de uma vogal” (CÂMARA JR., 1970, p. 56).

O conceito vogal epentética ou epêntese vocálica é usado por alguns autores para indicar tanto a vogal inserida em encontros consonantais heterossilábicos (consoantes em sílabas diferentes) quanto em encontros consonantais tautossilábicos (consoantes na mesma sílaba) que é o foco deste trabalho. Assim, nos dados de fala de língua polonesa dos informantes, utilizaremos a vogal epentética nas situações em que há a inserção de um elemento vocálico nos encontros consonantais tautossilábicos, como por exemplo, 


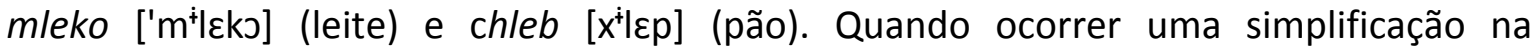
produção dos encontros consonantais, isto é, um apagamento, desfazendo o grupo, denominaremos tal ocorrência, conforme o Dicionário de fonética e fonologia (SILVA, 2011), de fenômeno da lenição, como em deszcz [dعf] (chuva).

Neste trabalho, descrevemos, por meio da fonética acústica, os encontros de sons consonantais tautossilábicos na língua polonesa falada em Cruz Machado. Selecionamos do corpus algumas ocorrências de encontros dos sons consonantais tautossilábicos (formados por consoantes em uma mesma sílaba), isto é, o conjunto de duas ou mais consoantes presentes numa mesma sílaba, que na língua polonesa são comuns, porém são inexistentes na língua portuguesa, tais como, registro ortográfico e transcrição fonética respectivamente, (chl) [xl], (ml) [ml], (krz) [ks], (szcz) [Jt']].

Examinamos acusticamente, buscando descrever sua realização em nosso corpus e verificar se há apagamento de algum som consonantal ou a produção da epêntese vocálica em encontros de sons consonantais tautossilábicos.

No quadro 3, listamos algumas palavras selecionadas com ocorrência de encontros de sons consonantais no polonês e inexistentes no PB e analisadas neste trabalho com o objetivo de verificar se há realização ou não de som vocálico entre esses encontros de sons consonantais ou apagamento de algum deles. Cada dado de fala foi editado separadamente e examinado para fins de análise acústica por meio do programa Praat (BOERSMA; WEENINK, 2016). Este estudo abarca dados de fala de oito informantes com quatro repetições das palavras-alvo, conforme quadro 3, examinamos acusticamente um total de 250 dados de produções de sons de encontros consonantais. 
Quadro 3-Palavras com encontros de sons consonantais

\begin{tabular}{|c|c|c|}
\hline Português & Polonês & Transcrição fonética \\
\hline abelha & pszczoła & 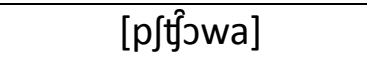 \\
\hline pão & chleb & {$[x \mid \varepsilon p]$} \\
\hline leite & mleko & [mlekJ] \\
\hline chuva & deszcz & {$\left[\mathrm{d} \varepsilon \int \hat{t}\right]$} \\
\hline cadeira & krzesło & [kşعșw)] \\
\hline onde & gdzie & {$[\mathrm{g} \overline{\mathrm{d} \zeta} \varepsilon]$} \\
\hline pássaro & ptak & [ptak] \\
\hline poço & studnia & [stud,na] \\
\hline
\end{tabular}

Neste estudo foram analisados dados com diferentes tipos de encontros consonantais como: nasal com lateral [ml], fricativa com lateral $[\mathrm{xl}]$, oclusiva com fricativa e africada [pft̂], duas oclusivas [gd] e [pt] oclusiva com nasal $[d, n]$, oclusiva $\mathrm{cm}$ fricativa [kş] e duas fricativas [jt̂]].

Nos encontros consonantais compostos pelas nasais e laterais como na palavra mleko ['mlekJ] (leite) prevaleceu a não realização da vogal epentética. Entretanto, alguns informantes inseriram epêntese na produção de mleko como mostra a figura 1. Já a figura 2 possibilita a visualização da produção de ['mlعko] sem elemento vocálico entre a nasal e a lateral. 
Figura 1 - Permite a visualização da realização de mleko (leite) como [' $\left.\mathrm{m}^{\dagger} \mid \varepsilon k J\right]$ marcada com uma elipse na cor azul e com a presença da epêntese entre a nasal e a lateral marcada com uma elipse na cor vermelha

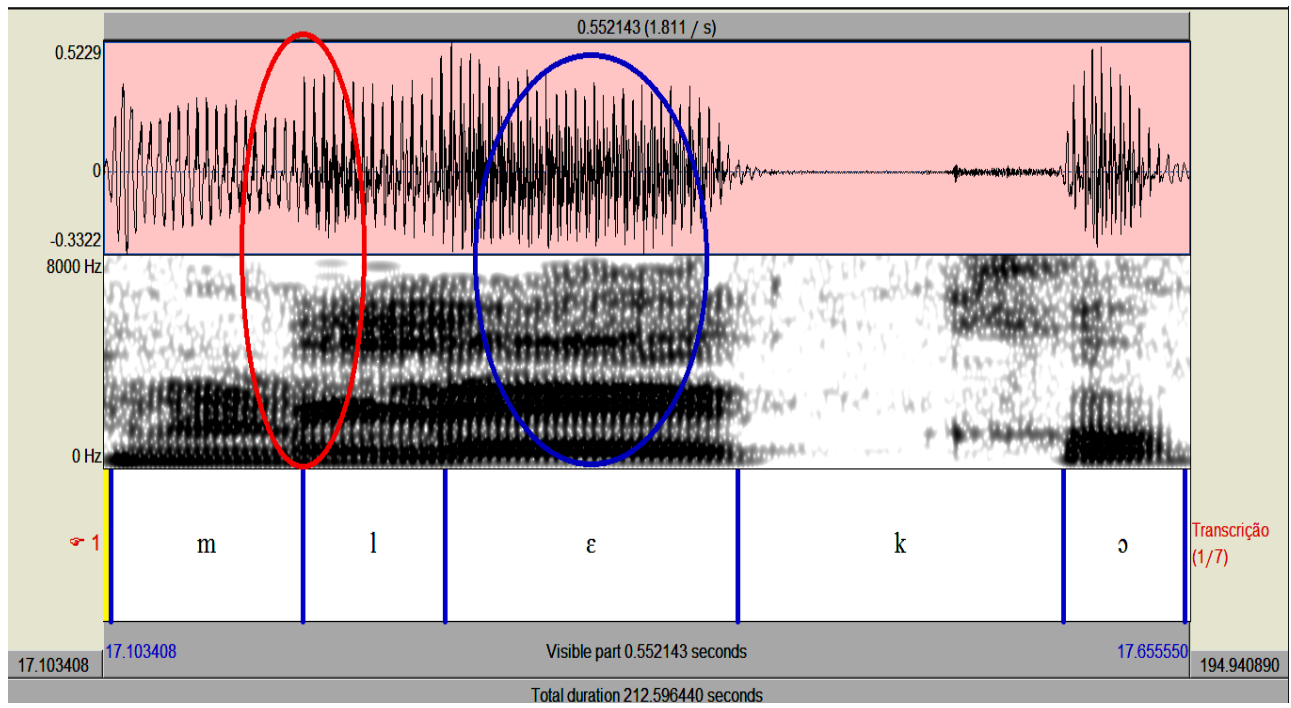

A figura 2 possibilita a visualização da realização de mleko (leite) como ['mlદko] da informante mais velha ID, exemplificando a não ocorrência de vogal epentética entre esse encontro consonantal.

Figura 2 - Permite a visualização da realização de mleko (leite) como ['mlekJ] marcada com uma elipse na cor azul, pela informante ID com 89 anos, e sem elemento vocálico entre a nasal e a lateral marcada com uma elipse na cor vermelha

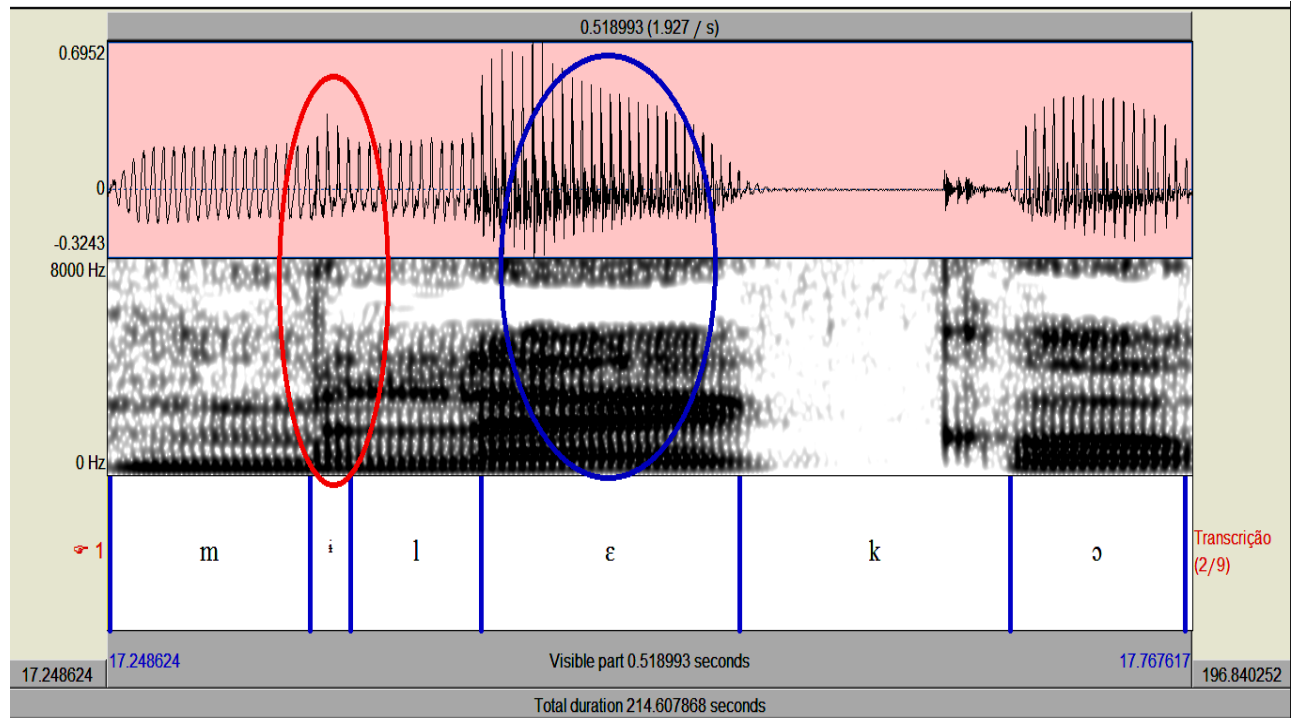


Para a produção de mleko, seis informantes, nas quatro repetições, não introduziram a epêntese vocálica entre o encontro de som consonantal [ml]. Uma informante, IL, com 68 anos, para as quatro repetições de ['mlekJ] inseriu o elemento vocálico entre a nasal e a lateral realizando mleko como [' $\left.\mathrm{m}^{\dagger} \mid \varepsilon k \jmath\right]$. Já uma outra informante, $A D$, com 37 anos, somente em uma das repetições introduziu a epêntese. No total de dados examinados no grupo [ml] predominou a ausência de som vocálico, com um percentual de $84,37 \%$ de realização, e com 15,62 \% de presença da epêntese entre a nasal e a lateral como visualizamos no gráfico 1.

Gráfico 1 - Percentuais de realização da vogal epentética no encontro de som nasal e lateral $[\mathrm{ml}]$
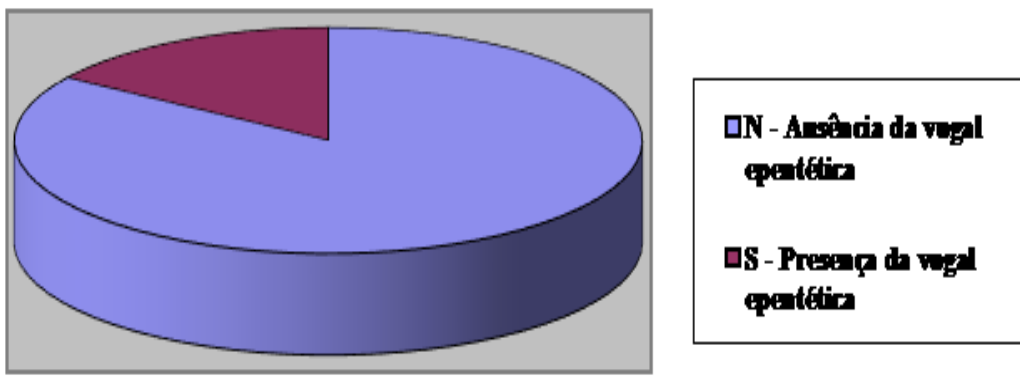

Na descrição do polonês falado em Mallet por Costa e Gielinski (2014), houve também a presença de elemento vocálico no encontro consonantal composto por som nasal e lateral, nesse caso também na palavra mleko. Nesse encontro consonantal [ml] predominou a ausência da epêntese, com $46 \%$ de percentual de realização, mas ocorreu também a produção da vogal epentética com um percentual $42 \%$, e ainda se constatou a realização de sons não identificáveis com $12 \%$ de percentual. Essa variação encontrada no polonês falado em Mallet é maior e se diferencia um pouco do polonês falado em Cruz Machado. A não realização do som vocálico entre o encontro consonantal [ml] em Mallet 
foi produzido pelos três informantes com maior faixa etária: um com 86 anos, outro com 79 anos e o terceiro com 61 anos. Já nos nossos dados, a informante IL, com 68 anos, inseriu a vogal epentética nas quatro repetições e uma informante do grupo com menor faixa etária introduziu o som vocálico em somente uma repetição. No polonês falado em Cruz Machado, parece que a faixa etária não exerce algum papel condicionante na presença de epêntese como na língua polonesa em Mallet.

No encontro consonantal entre a fricativa e som lateral "chl" [xl] predominou a não ocorrência de som vocálico, mas houve também variação na produção, como podemos perceber na figura 3 e 4 . Há presença de sons não indentificáveis (sem estrutura formântica clara). Na figura 4, por exemplo, parece que a informante introduziu um som não identificável entre a fricativa e a lateral.

Figura 3 - Realização chleb (pão) como [xlep] pela informante ID com 89 anos, marcada com uma elipse na cor vermelha e sem elemento vocálico entre a fricativa e a lateral marcada com uma elipse na cor preta.

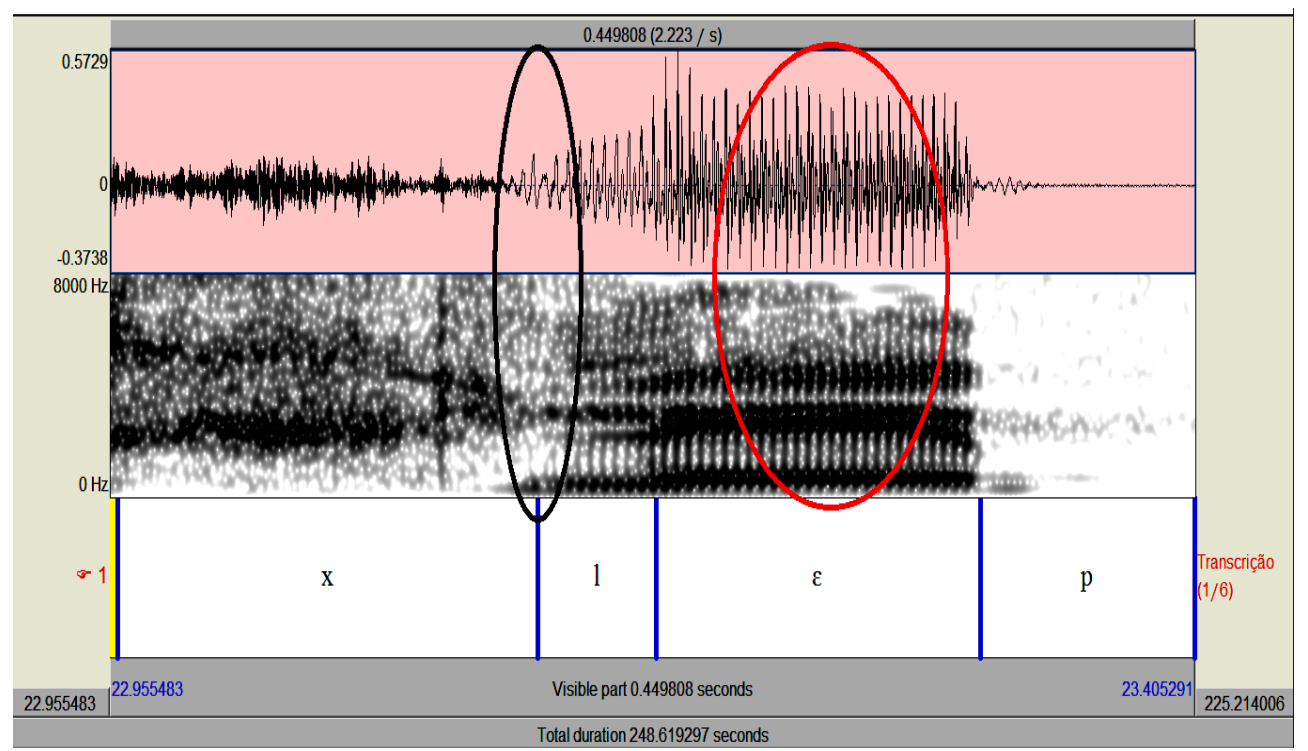


Figura 4 - Realização de chleb (pão) pela informante AD com 37 anos, com a inserção de um som não identificável entre a fricativa e a lateral, marcada com uma elipse na cor vermelha

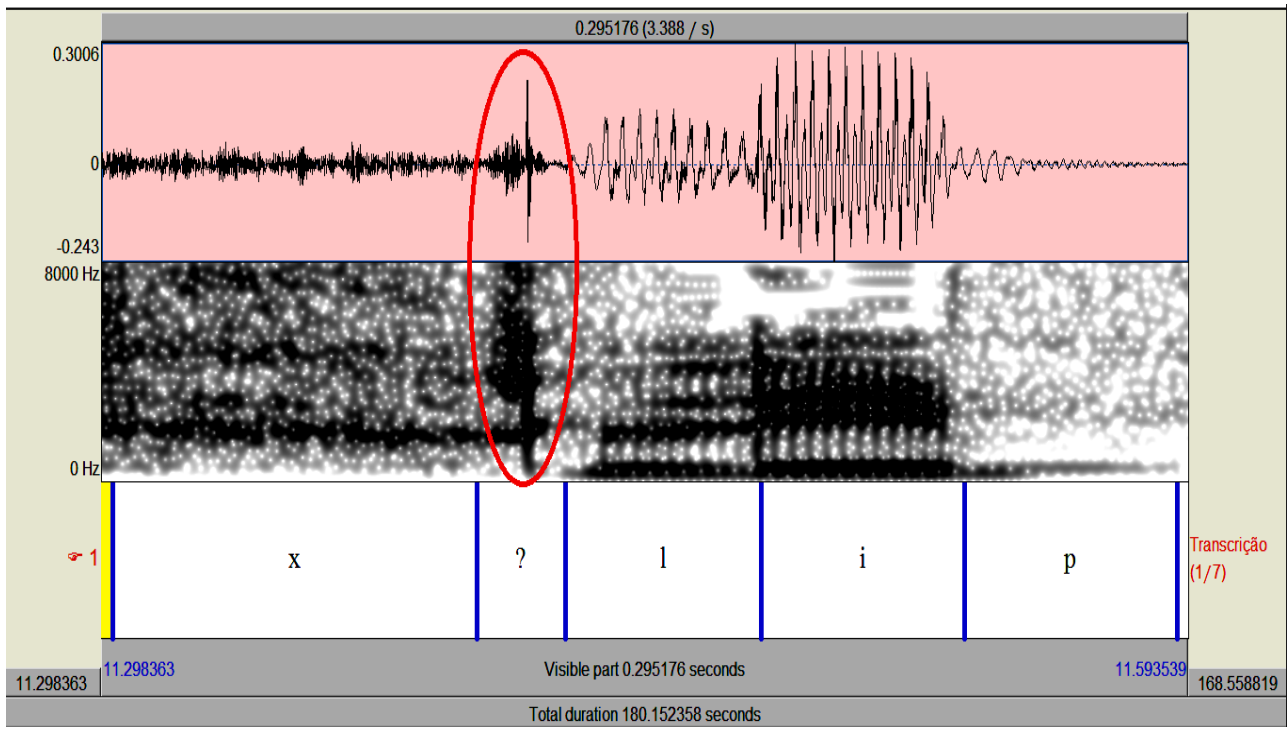

Para as quatro repetições de "chleb" (pão) a informante AD, com 37 anos, introduziu um som não identificado nesse encontro consonatal [xl] semelhante ao da figura 4. O gráfico 2 apresenta os percentuais de realização da palavra chleb. Como mencionamos, nesse encontro de som consonantal [xl], predominou a não inserção de som vocálico entre a fricativa e a lateral, com $56,25 \%$ de produção. Alguns informantes inseriram um som não identificável o que corresponde a $25 \%$. Os dados ainda demonstram que $18,75 \%$ introduziram a vogal epentética.

Gráfico 2 - Percentuais de realização de chleb (pão)

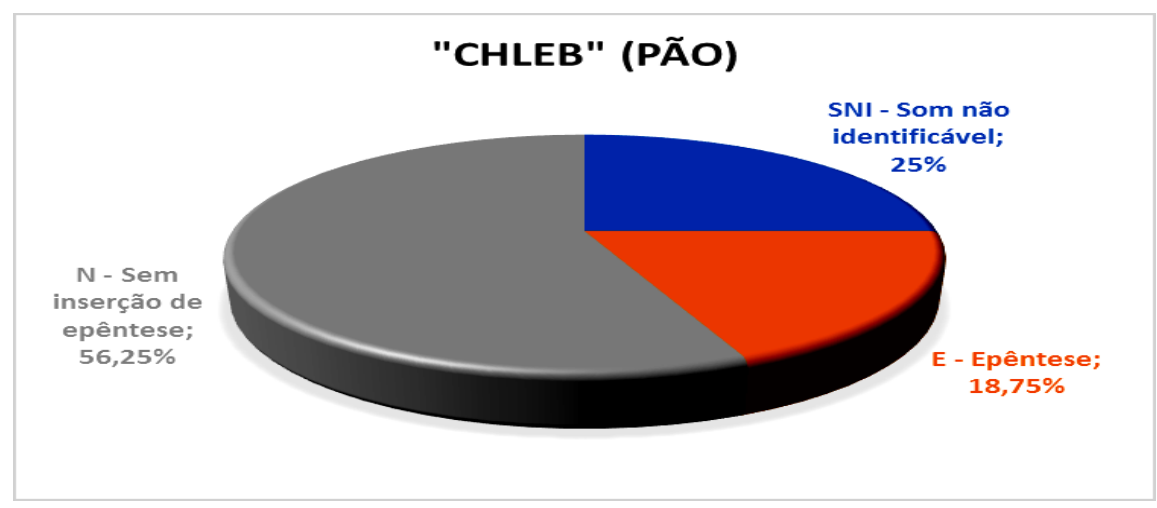


Nos dados de encontros consonantais das oclusivas encontramos também variação na produção. Como podemos visualizar na figura 5 , há uma simplificação na produção das oclusivas, isto é, há um apagamento da oclusiva inicial desfazendo o grupo, ocorrendo o fenômeno da lenição. No PB, um falante introduziria uma epêntese vocálica, pois há restrição fonotática nessa sequência, já os informantes desta pesquisa não produziram um som vocálico, mas adaptaram a fala com a simplificação, ou seja, apagamento de uma das oclusivas.

Essa variação é vista na produção de gdzie [g $\widetilde{\mathrm{d} z} \varepsilon$ ] (onde) entre os informantes, o que mais chama atenção é o fato de que um dos oitos informantes, com a maior faixa etária, produziu a oclusiva inicial [g], a informante ID com 89 anos, conforme visualizamos na figura 5 , sinalizada com uma elipse.

Figura 5 - Realização gdzie (onde) como [g $\overline{\mathrm{d} z ̋} \varepsilon$ ] pela informante ID, sem elemento vocálico entre as oclusivas $[\mathrm{g}]$ e $[\widehat{\mathrm{d} \zeta ̋}]$

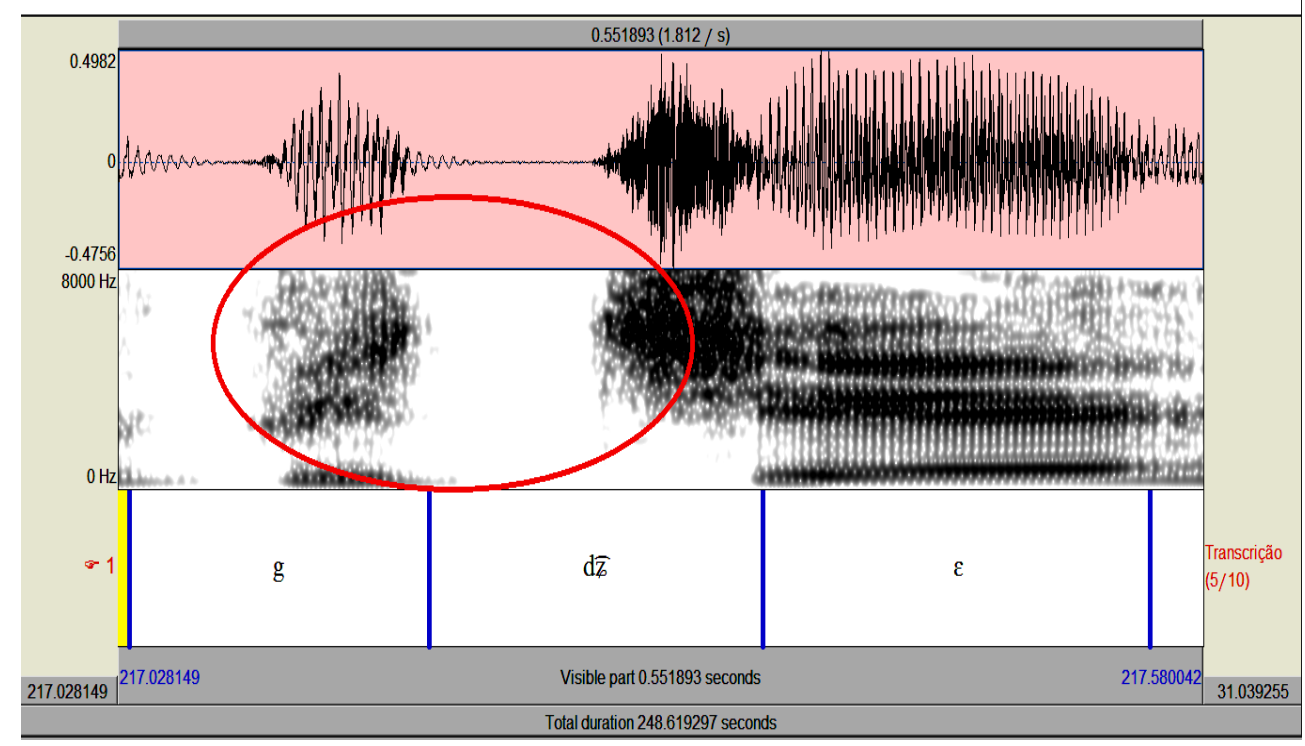

A discrepância das realizações de "gdzie" [g $\overline{\mathrm{d} z} \varepsilon$ ] da informante ID em relação às realizações dos demais informantes podemos perceber na figura 6 da informante $A D$ com 
37 anos, visualizamos a não realização do [g], entre a fricativa final da frase-veículo e da africada $[\widehat{\mathrm{d} z}]$.

Figura 6 - Realização gdzie (onde) como [ $\overline{\mathrm{d} z} \varepsilon$ ] pela informante $A D$, sem a realização da oclusiva [g]

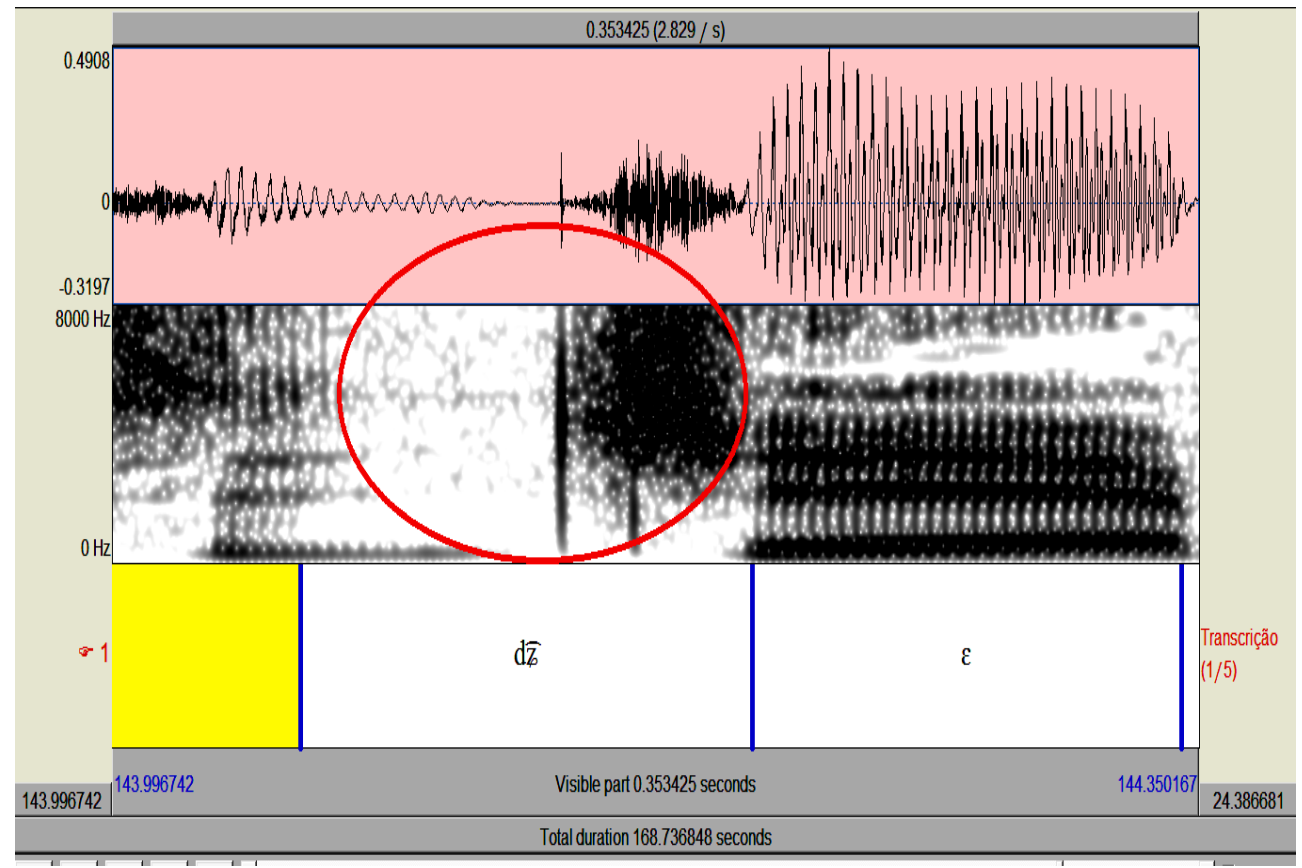

No gráfico 3, notamos os percentuais de não realização da oclusiva inicial [g] (SG), os percentuais de realização da oclusiva inicial [g] (CG), os percentuais de realização de som não identificável no início (SNI) e a produção de outra palavra pelos informantes em

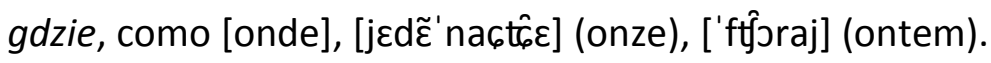

Gráfico 3 - Percentuais de realização de gdzie [g $\widetilde{\mathrm{d} z} \varepsilon]$

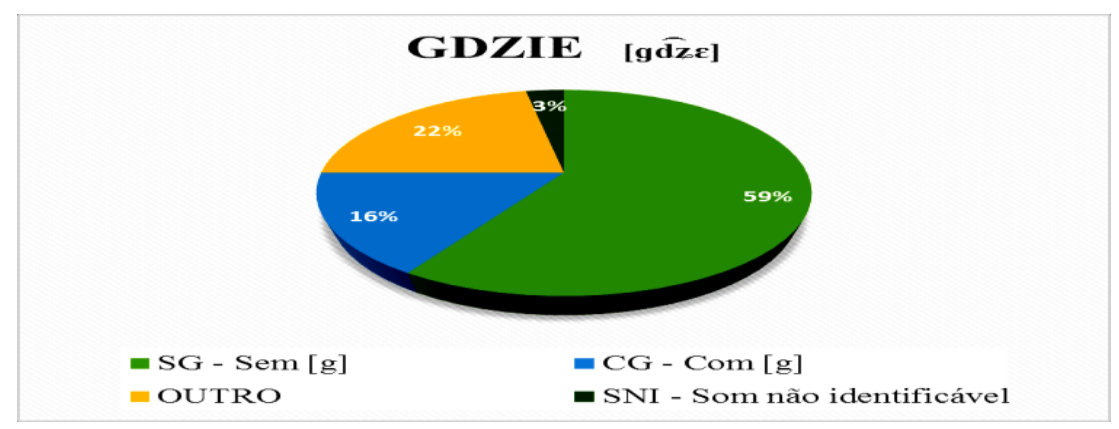


Com base no gráfico 3, podemos hipotetizar que a falante mais velha da língua polonesa, não adquiriu um novo sistema e/ou não ocorreu adaptação por conta da L2, levando em consideração a produção dos demais participantes.

Já no grupo de encontro consonantal de som de oclusivas e fricativas, cuja sequência não existe no PB, esperava-se que os informantes produzissem a vogal epentética, como, no caso do PB, a palavra "psicologia" geralmente produzida como [p'sikolozia].

No polonês falado em Cruz Machado, no grupo de encontro consonantal de som de oclusivas e fricativas, como por exemplo, na palavra pszczoła [p $\int$ ţ่วwa] (abelha) não houve produção de elemento vocálico, como visualizamos na figura 7, marcada com uma elipse na cor vermelha. No entanto, verifica-se uma redução do som fricativo conforme a figura 8.

Figura 7 - Realização da palavra pszczoła [p/t̂̉wa] (abelha) por ID com 89 anos, sem elemento vocálico entre o grupo consonantal [p $[\hat{t}]$, marcada pela elipse na cor vermelha

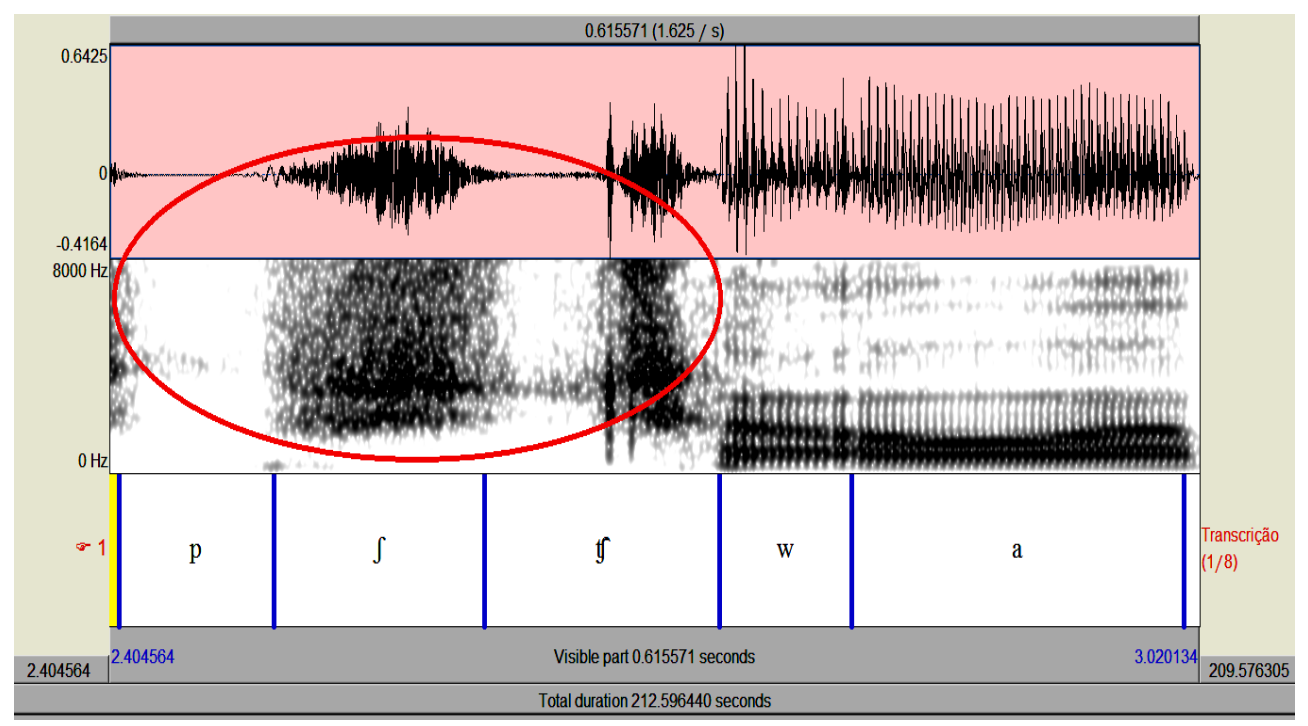


Notamos que a informante ID, mais velha, produziu primeiramente uma oclusiva desvozeada [p], em seguida uma fricativa desvozeda []] e posteriormente uma africada [ $t$ ] caracterizada pela obstrução total a um ruído trasiente (ruído de explosão) e seguida de um ruído contínuo de friç̧ão.

Nenhum dos informantes introduziu epêntese entre grupo consonantal no vocábulo pszczoła, no entanto, verificamos na produção dessa palavra em alguns dos participantes o apagamento da africada, repetindo o padrão de lenição encontrado nos grupos de duas oclusivas sonoras. Um dos informantes do grupo mais jovem produziu a palavra pszczoła com [p]Јwa], como podemos examinar na figura 8, sem a ocorrência da africada [ţ]. Na figura 8 , podemos verificar somente uma intensificação do ruído da fricativa []].

Figura 8 - Apresenta a realização da palavra pszczoła (abelha) como [p〕əwa]vpelo informante RN, sem elemento vocálico marcada pela elipse na cor vermelha

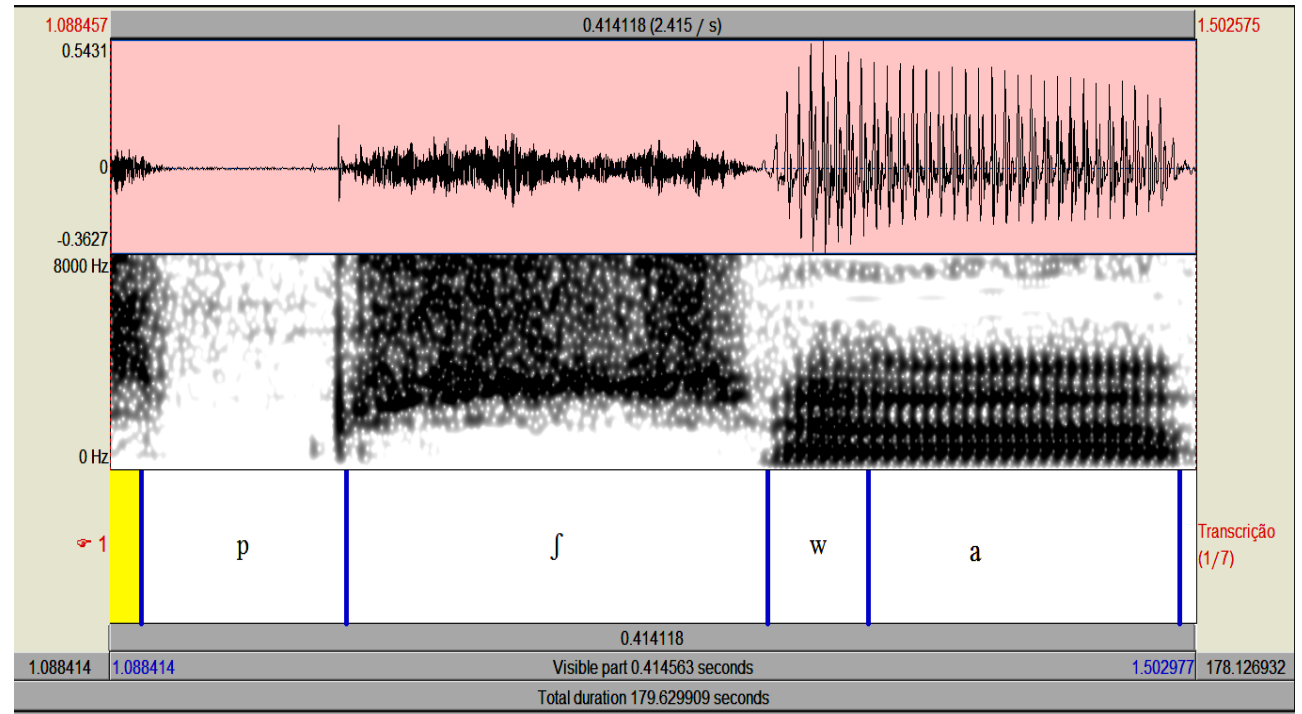


Característica semelhante apresenta o informante AD, que realizou "pszczoła" como [p]Јwa]. No entanto, é importante destacar que a informante mais nova do grupo realizou como [p fţ̧วwa] conforme visualizamos na figura 9.

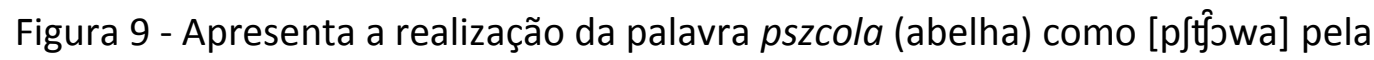
participante EB, sem elemento vocálico entre a oclusiva e as fricativas marcada pela elipse na cor vermelha

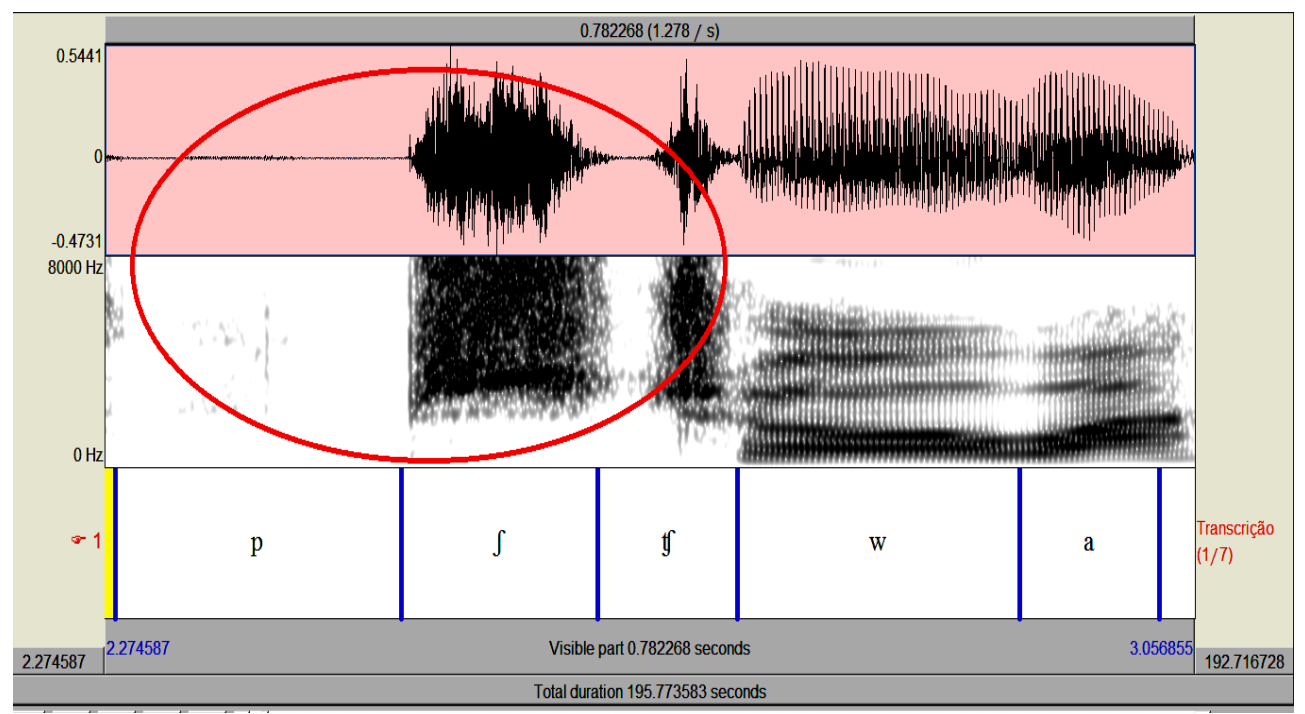

Ainda no encontro consonantal de sons oclusivos e fricativos tomamos o exemplo do vocábulo krzesło [kşsswo] (cadeira). Nesse dado, nenhum informante realizou epêntese vocálica. Não houve também variação na produção ou redução de fricativas, talvez isso não ocorra como no encontro anterior por se tratar apenas de encontro da oclusiva com uma africada, diferentemente da palavra pszczoła (abelha), onde há oclusiva, fricativa e africada, ocorrendo a simplificação. 
Figura 10 - Realização de krzesło (cadeira) como [kşعșwo] pelo informante LL, sem elemento vocálico entre a oclusiva e a fricativa marcada com uma elipse na cor vermelha

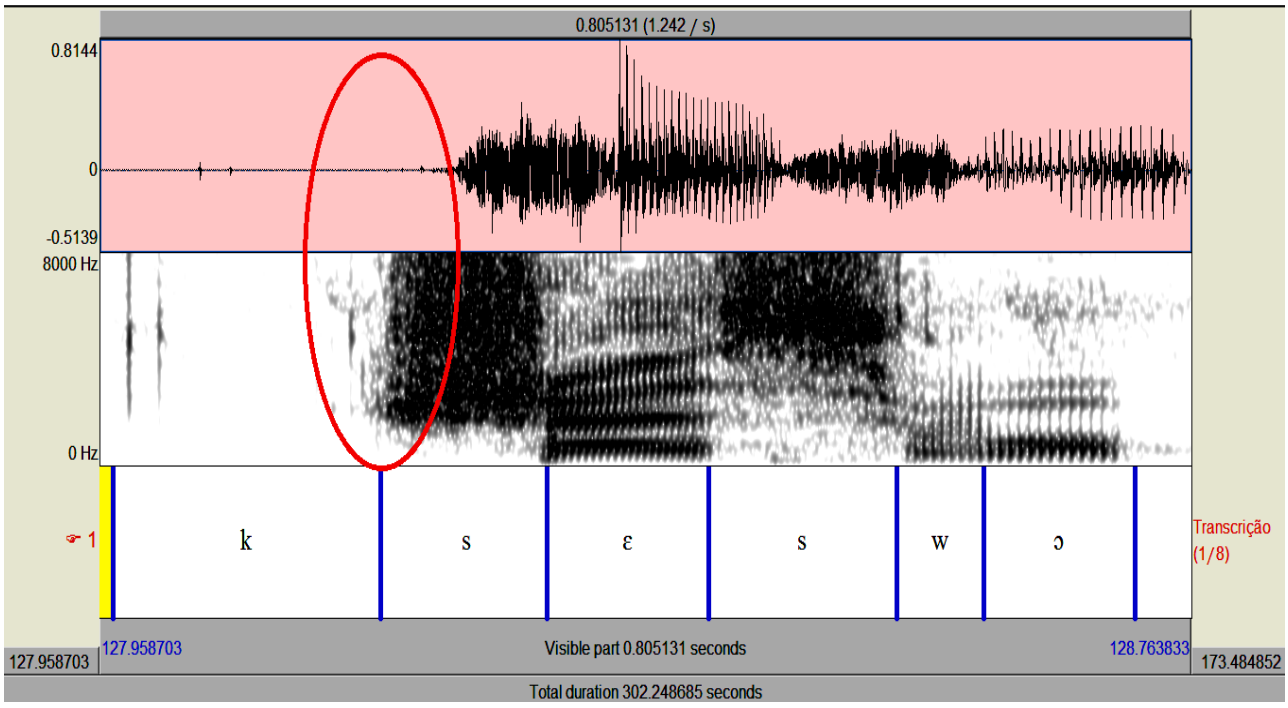

Nos dados do grupo de encontros consonantais de sons fricativos podemos citar o vocábulo deszcz [defţ], com sequência de fricativa []] e africada [t]. Nesses dados examinados, constatamos que alguns informantes repetiram o padrão de lenição encontrado no grupo da oclusiva, fricativa e africada, apagando a africada na produção do som. Impressionante que os três informantes mais velhos e a informante mais nova produziram deszcz com características semelhantes, produzindo a fricativa e africada final []t̂] conforme mostra a figura 11. 
Figura 11 - Produção de deszcz (chuva) como [difț], pela informante mais jovem EB, sem elemento vocálico entre a fricativa e a africada marcada com uma elipse na cor vermelha

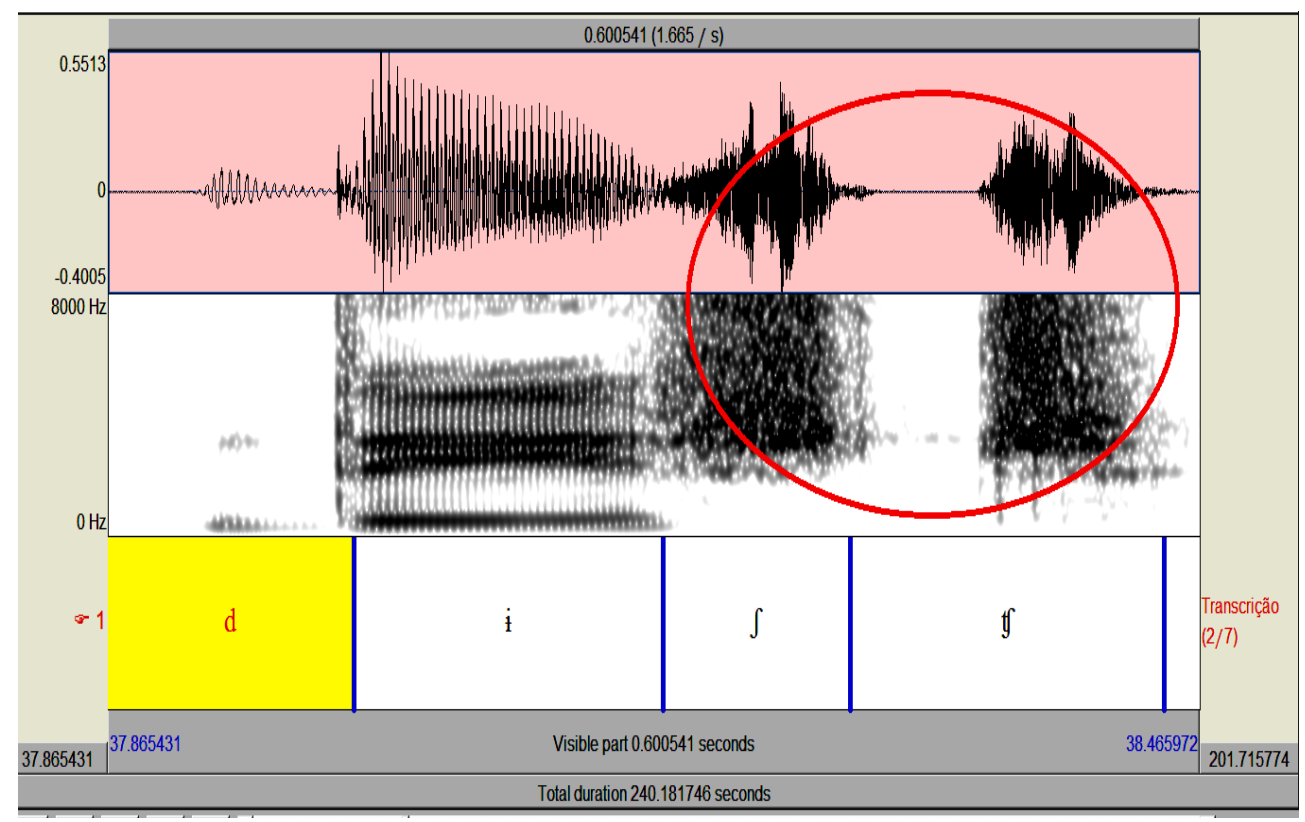

Nos dados de encontros consonantais das oclusivas desvozeadas [pt] como no vocábulo ptak [ptak] (pássaro) não houve a introdução da epêntese, bem como, não se verificou o fenômeno da lenição. Da mesma forma, no encontro consonantal da oclusiva vozeada [d] com a nasal [n], como na palavra studnia [stud,na] (poço) não constatou-se nenhum desses fenômenos (epêntese e lenição).

\section{Considerações finais}

Este trabalho, parte da dissertação do mestrado, analisa o fenômeno da lenição e da inserção da vogal epentética nos encontros de sons consonantais tautossilábicos, inexistentes no PB, do polonês falado no município de Cruz Machado, mais especificamente na comunidade do Rio do Banho. Os descendentes de poloneses,mantiveram a religiosidade, os costumes e a língua de seus antepassados, 
transmitindo a seus filhos e netos. Essa peculiaridade é vista na quarta ou até quinta geração cujos descendentes preservam o idioma e a identidade. A língua polonesa predomina no uso diário (trabalho na agricultura), reuniões familiares, entre os amigos e na igreja. Devido ao isolamento desse município e a atuação de agentes culturais - essa riqueza não foi esquecida ou apagada por seus descendentes - um pedaço da Polônia antiga (mais de cem anos passaram), que sob o Rio Wisła já não é mais lembrada.

$\mathrm{Na}$ análise acústica dos encontros de sons consonantais, os resultados mostram que os falantes mantêm um sistema do polonês estável, predominando a ausência da epêntese vocálica. Apenas nos encontros consonantais compostos pelas nasais e laterais como na palavra mleko ['mlekJ] (leite) ocorreu a introdução do elemento vocálico entre a nasal e a lateral e nos encontros consonantais entre a fricativa e som lateral "chl" [xl] houve a presença de um elemento vocálico não identificável, com a estrutura formântica não clara.

Além da epêntese ocorreu nos dados também o fenômeno da lenição, gerando a simplificação dos encontros consonantais. Constatou-se que alguns informantes simplificaram encontros consonantais na produção, como por exemplo, em pszczoła (abelha). Nesse grupo de encontro consonantal de som de oclusivas, fricativas e africadas, alguns participantes apagaram a africada, repetindo o padrão de lenição encontrado nos grupos de duas oclusivas sonoras, como em gdzie [g $\overline{\mathrm{d} z} \varepsilon$ ] (onde) com o apagamento da oclusiva inicial, dessa forma desfazendo o grupo.

Como perspectivas futuras, com a conclusão do mestrado, pretendemos investigar acusticamente outros detalhes fonéticos da língua polonesa falada em Cruz Machado, como as vogais, principalmente a vogal [i] centralizada, os sons fricativos palatais e 
retroflexos e as laterais, ampliando a análise e contribuindo para o conhecimento do plurilinguismo existente no Brasil.

\section{Referências}

ALTENHOFEN, Cléo V. Política linguística, mitos e concepções linguísticas em áreas bilíngues de imigrantes (alemães) no Sul do Brasil. Revista Internacional de Linguística Iberoamericana (RILI), Frankfurt, v. 2, n. 1, p. 83-93, 2004.

BAGNO, Marcos. Preconceito linguístico: o que é, como se faz? 49. ed. São Paulo: Loyola, 2007.

BOERSNA, Paul.; WEENIK, David. PRAAT doing Phonetics by Computer. University of Amsterdam. Versão praat5342_win32zip (2 March 2016).

CÂMARA JR, Joaquim. Estrutura da língua portuguesa. 25. ed. Petrópolis: Vozes, 1970.

COSTA, Luciane Trennephol; GIELINSKI, Márcia. Detalhes fonéticos do Polonês falado em Mallet. Revista (Con) Textos Linguísticos. v. 8, n. 10, p. 159-174, 2014. ; LOREGIAN-PENKAL, Loremi. A coleta de dados do banco VARLINFE - variação linguística de fala eslava: peculiaridades e características. Revista Conexão UEPG, 11 (1), 100-110, 2015.

DVORAK, Anna. A hidden immigration: the geography of Polish-Brazilian cultural identity. Tese de Doutorado. Los Angeles: University of California, 2013.

FANT, G. Acoustic theory of speech production. The Hague: Mouton, 1960.

GUSSMANN, Edmund. The phonology of Polish. New York: Oxford University Press, 2007. IBGE - Instituto Brasileiro de Geografia e Estatística. Disponível em: <www.ibge.gov.br>. Acesso em: 13 maio 2017.

KENT, Raymond; READ, Charles. The Acoustic analysis of speech. San Diego: Singular Publishing Group, 1992.

MAZUREK. Jerzy. A Polônia e seus emigrados na América Latina (até 1939). Goiânia: Espaço Acadêmico, 2016. 
OLIVEIRA, Nívia. A. Variação em encontros consonantais tautossilábicos no português brasileiro. 2017. Dissertação (Mestrado em Linguística) - Universidade Federal de Minas Gerais, Belo Horizonte, 2017.

SILVA, Thais. C. Dicionário de fonética e fonologia. São Paulo: Contexto, 2011. Fonética e fonologia do português: roteiro de estudos e guia de exercícios. 10. ed. São Paulo: Contexto, 2010.

Recebido em 05 de setembro de 2018.

Aceite em 11 de outubro de 2018.

\footnotetext{
'Informações disponíveis no endereço eletrônico <www.ibge.gov.br>. Acesso em 20 jan. 2017.

ii Informações disponíveis no endereço eletrônico <www.ibge.gov.br>. Acesso em 13 maio 2017.

iii Frases veículo são recursos usados durante a gravação dos dados de fala para uniformização dos contextos anteriores e posteriores de produção.

${ }^{\text {iv }}$ Esse programa pode ser obtido gratuitamente na internet no seguinte endereço: <http:\|www.praat.org>.

` Mallet é outra cidade marcada pela imigração eslava e vizinha de Cruz Machado.
} 